\title{
Exploration on Port-city Integration Development Mode under Regional Pattern - Take Spatial Development Planning of Wuhan Newport for Example
}

\author{
Xiaojun Zhang \\ Wuhan Technology and Business University, Wuhan, 430065, China
}

\begin{abstract}
Keywords: Spatial development planning of Wuhan Newport; Regional pattern; Port-city integration; Development mode
\end{abstract}

\begin{abstract}
With the development of regional integration trend, port and hinderland have formed a new port-city relationship and shown significant features - strengthening of cooperativity, integration density and integration degree. To adapt to the development of this trend, Wuhan Newport changes the port development mode so as to comply with the demand of era development, i.e. achieve the development goal of "city-port integration and joint development" . On this basis, this paper mainly discusses port-city integration development mode under regional pattern in the spatial development planning of Wuhan Newport.
\end{abstract}

\section{Introduction}

Port is amphibious transportation equipment. Ships can complete secure access, transportation and berthing via a port. With the stable growth of national social economic situation and the comprehensive development and improvement of functions, ports can provide comprehensive service business. Functions of Chinese ports gradually penetrate into such fields as logistics, commerce and industry through the intermediate function of passenger and cargo transportation. With the development of traditional transfer business, ports start to develop various businesses such as packaging, processing, storage, distribution and provision of logistic and information services constantly and provide integrated logistic services with high additional value for customers in order to develop transportation business better. Wuhan Newport is developing into a multi-functional modern port. As ports can give full play to regional advantages, it develops industrial port and modern logistics around the port, strengthens the port construction, develops port-surrounding industry and accelerates the process of regional economic integration development while following the development step of heavy chemical industry in China.

\section{Analysis on development of Wuhan Newport}

\section{Analysis on development stage of port and hinderland areas in Wuhan}

(1) Formation stage. The development of hinderland economy requires the exertion of opening features of port. Port and hinderland need to be linked and achieve the complementation of flow of internal and external substances (cargo, fund, technology, information and personnel) through the circulation of various commodities with port as the link. Formation stage is characterized by a small number of channels between port and hinderland, low throughput and a small number of various factors of their flow. The junction of port and hinderland is mainly regions with high economic density and strong complementarity. (2) Initial development stage. Port and hinderland have more and more frequent exchange and economic regions gradually develop into a large scale. In this development process, ports have increasingly enhanced connection and attraction, finer internal division of labor, more specialized industrial structure and spatial arrangement and reasonable functional division of labor and show integration development trend. (3) Senior development stage. Port and hinderland in the senior development stage have very smooth connection, more frequent external linkage and closer connection of each internal part. The development of division system among hinderlands and between hinderland and port is more improved. In this stage, industrial 
structure and regional distribution are optimized to the greatest extent and external and internal factors achieve high intensification. (4) Dynamic adjustment stage. According to the development law of things, each thing has its life cycle and finally heads towards death. Port and hinderland economic areas experience high development period and gradually take a downhill path. In other words, after experiencing high intensive development of various internal factors of port and hinderland economic areas, their state of continual optimization no longer exists. They have various changes with the development of time, thus causing unbalance in the final development stage. It is very likely that functions of the overall division system will change. However, all want to maintain the "optimization" state for the longest time in the development of regional economy. To achieve this goal, people take measures consciously to control its decline speed, adjust measures in time according to the specific situation and complete the adjustment and optimization of its development process.

\section{Basis status of Wuhan Newport}

The emergence of Wuhan Newport has its special background conditions. Under the policy of the rise of central China and the construction of resource-saving and environmentally friendly society, Wuhan, Hubei becomes a key demonstration base. To promote the development of regional economy, Wuhan has built the Yangtze River transportation center and proposed a series of construction thoughts, projects and measures. Wuhan Newport has superior geographic location. It is located in the east of Wuhan city circle and the middle and lower reaches of Yangtze River. The original Wuhan Port and some port districts in Huanggang City, Ezhou City and Xianning City are its important constituent parts. It is a pivotal port along the Yangtze River as well as a port with rich high-quality resources in Hubei Province.

\section{Port-city integration development mode of Wuhan Newport}

In the current stage, the development mode of Wuhan Newport presents new development characteristics and integration trend, i.e. "port-city separation and interaction and appropriate separation among ports". The adoption of this development mode promotes closer and more harmonious relationship between port and city, i.e. “joint development”. Main patterns of manifestation of such development mode: first, port is an overwater bridge leading to city and the development of city relies on port for cargo supply; second, port and city develop jointly and promote each other and have mutual dependence; third, port promotes urban exchange and connection and is the support of city development. The development mode of Wuhan Newport and that of port city have the wonder of using different approaches to achieve equally satisfactory results. Their development involves the train of thought of integration. Under the mode of "joint development and integration of port and city" , their relation becomes closer. With the strengthening of regional economic integration trend, the development of port-city relationship is required to head towards a higher direction, make the relationship between port and city and that between port and hinderland closer and achieve cooperativity, intensification and integration better. With the development of intensification of port-city relationship, the degree of opening to the outside world of city is required to be higher and the penetration relation among cities, between port and city, and between port and hinderland is more obvious. Their relation is more complicated and closer. Therefore, consideration should be given to the coordination of their spatial, time and functional division and the harmony among the society, culture, environment and humanity during the planning of port city construction. Only with the harmonious and stable development of multiple factors can rapid construction and development of port city and its flourishing scene can be achieved. 


\section{Spatial development planning route of Wuhan Newport in port city integration development under regional pattern}

\section{Reasonable layout of regional urban space}

Wuhan city circle includes multiple development regions, among which Wuhan Newport town cluster is one of the most important development objects. The objective is to develop Wuhan Newport town cluster into a harmonious and coordinating town concentrated area with uniform order, achieve the model of independent town development, establish a metropolitan center, develop coastal ports into a window leading to the external world, develop Newport into various nodes, form a highly centralized transportation line network and finally establish an urban tribal group characterized by integrated and network development. It is required to plan development strategies for Wuhan Newport according to actual specific situation of Wuhan, provide adequate development space for town development and finally identify “one belt and multiple corridors, two axes and three districts" as the spatial development pattern of Wuhan Newport. First, "one belt" refers to the development of relevant industries of port such as port logistics and modern manufacturing with ports along the Yangtze River as development support and port city as spatial carrier and the constant improvement of opening degree of ports and service level and quality with the strategic development thought of going out. Second, “multiple corridors" mean that unique natural resource advantages of town such as mountain and water are utilized to determine its development direction according to the actual situation of town development, develop the town into a characteristic ecological landscape corridor. However, the harmonious development of human and nature should be ensured and ecological balance should be maintained. Third, "two axes" refer to the development axis with Wuhan as the core. Wuhan Newport town cluster is divided into two parts - the east and the southwest. The development of eastern town cluster benefits from Shanghai-Chongqing Expressway and is characterized by successive cities. The development of southwest benefits from Beijing-Hongkong-Macao Expressway and is characterized by point-axis expansion and cluster promotion. Forth, "three districts" mainly include Newport integrated development district in Wuhan metropolitan area, Wuhan-Ezhou-Huanggang Newport development district and Wuhan-Xianning Newport development district.

\section{Optimization of industrial structure of port}

With the trend of domestic and foreign industrial development and transfer, Wuhan Newport closely combines port resources and location advantages according to stated development objectives and improves the optimization degree of port industrial structure with three major industrial bases as main development objects. Industries such as steel, coal, petrifaction, electricity, metal smelting, mechanical manufacturing and food processing are pillar industries in the central region. Food production, energy materials and modern equipment manufacturing and high and new technology are three important industrial bases. The construction and development of Wuhan Newport benefit from the development of Yangtze River shipping. Container transfer will become the development core of logistics service. Specialized and diversified port-surrounding industrial clusters will be created with heavy industry mainly involving energy, chemical engineering, steel and ship building and modern manufacturing mainly involving processing and electronics. Meanwhile, for the adjustment and optimization of port industrial structure, it is necessary to promote the development of heavy industry, manufacturing and supporting modern service industry, take relevant measures to promote the development positively, create a high-quality and high-level logistics service center in the port city and promote the coordinated development of urban economy and regional economy.

\section{Optimization and improvement of port collecting and distributing network}

The construction and development of Wuhan Newport should follow a vision of contact and development. On the one hand, it is required to take effective measures to increase the throughput capacity of the port. On the other hand, importance should be attached to establish collecting and distributing system and achieve the optimization of throughput structure, coordinated and stable development of port and region, surrounding areas of Newport and hinderland areas and the 
sustainable development of Wuhan Newport. National trunk highway and railway are traffic foundation of the development of Wuhan Newport. Local channels and railway special line in the port district play a role as traffic backbone in the development of Newport. Overwater business, passenger transport and tourism traffic lines set up in eastern and western ports can effectively release traffic pressure and facilitate the timely communication with Wuhan Newport business district, port-surrounding new city, port industrial park and tourist attractions along the river. The development of Wuhan Newport requires the formation of a set of complete comprehensive transportation system and close connection between port and city, especially newly planned targets including Xianning port, Ezhou and Huanggang port areas. Ezhou and Huanggang port districts play a transitional role as a connecting link. In the central region with higher development level, water transportation and road transportation can be combined, which can promote the development of economy and trade and improve the contribution of port to urban development and the effectiveness of regional economic development. As Wuhan Newport is composed of eastern and western port groups, the construction of collecting and distributing network in port groups admits of no delay. In allusion to the construction of eastern port groups, a system for the evacuation of cargoes from port composed of road network, a railway channel along the river and two railway channels vertical to the river should be established, i.e. the so-called "six longitudinal, three horizontal and six interconnected channels” system. For the construction of western port groups, a system for the evacuation of cargoes from port composed of road network, two railway channels along the river and three railway channels vertical to the river should be established, i.e. the so-called "three longitudinal, three horizontal and three interconnected channels” system. Only with the realization of transportation network construction in the west and east can a perfect collecting and distributing network be established. Only with a developed collecting and distributing network can the port development give play to its advantages, closely connect with hinderland areas and promote healthy, sustainable and coordinated development of port city and regional economy.

\section{Dispersion of regional traffic system}

The transportation in Wuhan Newport and transportation lines in its surrounding areas jointly develop into a huge transportation system, which promotes the mutual exchange of internal production factors such as human, substance, fund and information, realizes reasonable and effective allocation of resources in the whole region and improves the integrity and intensification of regional development. The development trend of regional economic integration becomes increasingly obvious. With the promotion of port construction, especially the planning of transportation line, planned roads mainly involve railway, waterway and highway and a highly developed transportation network has formed. The transportation of cargo, distribution of cities and towns and good connection between national traffic system and ports result in a traffic information network with Wuhan Newport as the center. According to the planning of this traffic network, there is only a two-hour distance to the urban circle of Wuhan and most regions in Hubei Province, five-hour distance to Hunan, Henan, Jiangxi and Anhui and eight to ten-hour distance to some regions in Chongqing, Sichuan, Shaanxi, Shanxi, Yunnan and Guizhou.

\section{Conclusion}

Port and hinderland have countless ties, supplement each other and develop jointly. The development of port is an inexhaustible power of city development, while city provides various basic conditions for the development of port. With the strengthening of regional economic integration trend, the relationship between port and hinderland changes with the development of port-city relationship, which is mainly manifested as cooperative degree, intensification and integration in the current stage. Therefore, Wuhan Newport explores a path appropriate to port-hinderland urban regional economic integration development mode for achieving the development goal of "city-port integration and joint development" of Wuhan Newport gradually according to the actual situation of local development in combination with relevant domestic and foreign theories. 


\section{Acknowledgments}

This paper is humanistic and social sciences research project of Hubei Education Department in 2014, "Development of Free Trade Area in Middle Reaches of Yangtze River -Research on Construction of Wuhan Newport Tax-protected Zone”, Project No.: 14G475.

\section{References}

[1]] Wang Zhimin et al. Research on Degree of Contribution of Yantian Port to Regional Economy and Its International Development, Shanghai: China Communications Press, 2013,(12).

[2] Gao Qin. Research on Interactive Relationship between Container Transportation in the Port and Regional Economic Development. School of Transportation, Wuhan University of Technology, 2011.

[3] Wang Shihao. Zhangang - Strategies for Optimization and Development of Productivity Structure in Hinderland. Regional Research and Development, 2014,(04).

[4] Zhang Chunling, Ma Yuman. Research on Strategies for Interactive Development of Ports in Tangshan and Urban Economy. Industrial Technology Economics, 2013,(05).

[5] Yu Qianqian, Wan Yanhua. Research on City-Industry Interaction Pattern and Planning Strategy

- Take Northern Industrial City in Yong'an for Example. Diversification and Tolerance - 2012 Memoir of Annual Conference on Urban Planning in China (01. Research on Urbanization and Regional Planning). 2012. 